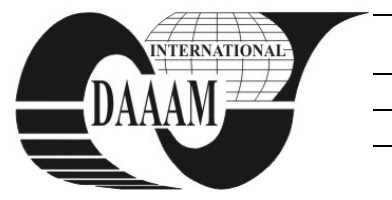

Annals of DAAAM for 2011 \& Proceedings of the 22nd International DAAAM Symposium, Volume 22, No. 1, ISSN 1726-9679 ISBN 978-3-901509-83-4, Editor B. Katalinic, Published by DAAAM International, Vienna, Austria, EU, 2011 Make Harmony between Technology and Nature, and Your Mind will Fly Free as a Bird Annals \& Proceedings of DAAAM International 2011

\title{
ANALYSIS OF INFLUENCING FACTORS ON STYLUS CALIBRATION OF CMM
}

\author{
STRBAC, B[ranko]; HADZISTEVIC, M[iodrag]; VRBA, I[gor]; RADLOVACKI, V[ladan] \& HODOLIC, \\ J[anko]
}

\begin{abstract}
The result of the measurement on a coordinate measuring machine (CMM) depends on many factors. Calibration accuracy of the styli is one component of inaccuracy. Inaccuracies occurring during the calibration and verification stylus have an effect on all measuring results. Influential factors in the calibration process, such as accuracy of the calibration sphere and the environmental conditions are not considered in this study. This paper analyses the results of the calibration depending on the calibration sphere direction on the machine table and the displacement of the calibration contact starting point in the positive direction of the $x$ axis. In the paper two-factor analysis of the variance belonging to the method ANOVA is compared to the influences of qualitative variables and accuracy.
\end{abstract}

Key words: CMM, calibration styli, accuracy, ANOVA

\section{INTRODUCTION}

In CMM, there are many error components that lead to uncertainties. One of the errors includes the probing system calibration (stylus calibration) and it has a critical role in the CMM measurements, not only in terms of the functionality, but also in terms of the contribution towards the overall measurement error. The probing system in CMM includes a stylus and a stylus tip that have own dynamic characteristics during the measuring process (Salah, 2010). The contact between the stylus tip and the detected surface is the source of signals developing the pattern on the working objects. Hence, the performance of the CMM system is in a great deal determined by the motion precision of the probe tip and its actuator. The probe stylus tip is at the centre of the CMM operation and a key element of coordinate measurements. The exact calibration of the stylus is the basic requirement for all measurements. Any deviation caused by an inadequate or incorrectly performed calibration process will affect every measurement to be done with the probing system, i.e. the measurement results could have significant errors.

\section{CALIBRATION STYLUS}

The position of the tip ball centre point related to the reference point of the probing system and the radius of the tip ball must be known in order to perform correct measurements. These parameters are dependent on the probing force (magnitude and direction), elastic behaviour of a probing system, stylus, workpiece and other factors. Origin of these impacts can be found among materials, components, arrangement of components in the probing system, dimensions like length, diameter of styli, material properties, and elastic flexibility of stylus joints, including suspension and roundness deviations of the tip ball.

Due to the necessary accuracy and the complexity of interactions, they cannot be calculated. They can be determined experimentally for a virtually ideal probing system with a virtually stiff stylus with an effective tip ball diameter using a calibrated artifact under the same conditions as the performance of the

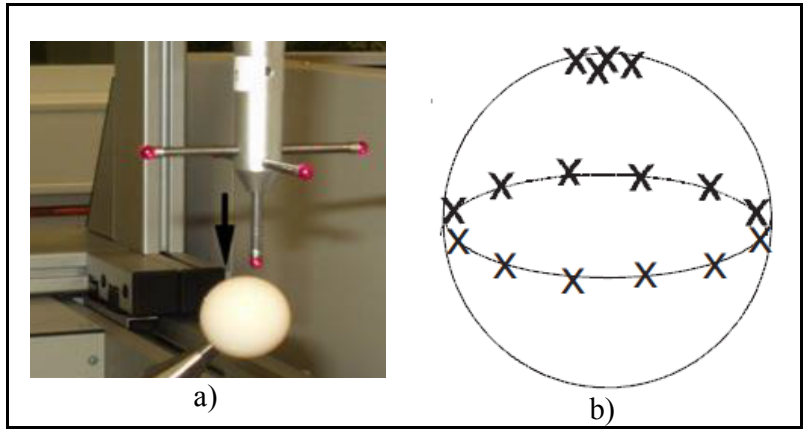

Fig. 1. An example for a calibration stylus. (a. probing of calibration artifact; $b$. probing strategy with 16 points)

subsequent measurement. This procedure is called the probing system calibration (Weckenmann et al., 2004).

Calibration is a fundamental action in managing sensors and of the entire measuring cycle (Figure 1). Calibration consists of the identification of diameter and of the position of the centre artifact with respect to the origins of the CMM reference system. In essence, calibration defines where the probe (stylus) is located, and nullifies the effect of probing forces on accuracy (Roithmeier, 2007).

Since the calibration stylus impacts the results of all subsequent measurements up to the next calibration, a small uncertainty has to be ensured. This requires clean surface of the reference sphere and the tip ball to be calibrated.

The calibration strategy includes in particular:

- Choice of calibrated artifact

- Choice of location and orientation of artifact

- Definition of number, location and sequence of probing points (for scanning mode: scanning lines, data rate, travelling speed).

\section{EXPERIMENT}

Calibrations (calibration stylus $\mathrm{r}=1.5 \mathrm{~mm}$ ) were carried out in the Metrology Laboratory at the Faculty of Technical Sciences in Novi Sad, Serbia, using a coordinate measuring machine Carl Zeiss CONTURA G2 RDS (Figure 2). The calibration process of the measuring stylus depends on the type of the measuring head with the inserted probing system. This experiment utilizes the RDS turning measuring head with the combination of VAST XXT scanning measuring sensor .

Calibration procedure is performed automatically, with exception of the first calibration where the operator has to provide the contact between the measuring stylus and the reference sphere $(\mathrm{r}=12.5 \mathrm{~mm})$. This contact should take place at the lowest point of the stylus and the highest point of the calibration sphere. This point ideally belongs to the axis line of both the stylus and the axis line of the reference sphere.

Since we can never be sure that system is set ideally, this paper determines the dependence of the calibration results and the deviation of the contact point (Figure $3 \mathrm{a}$ ) - factor A. The 


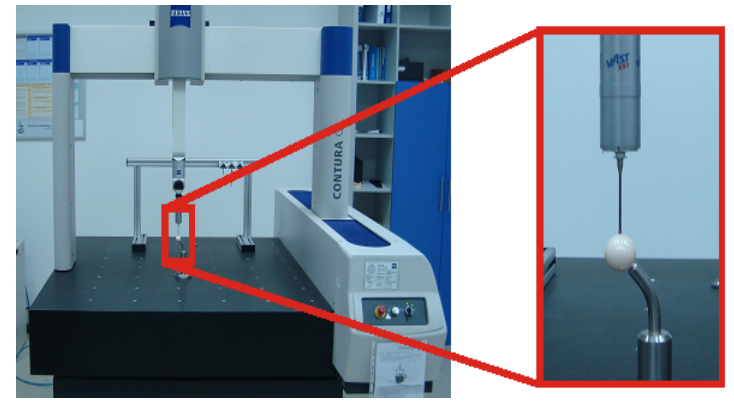

Fig. 2. CMM Carl Zeiss CONTURA G2 RDS, reference sphere and stylus.

calibration process for the stylus is performed in every contact point of the measuring stylus and the reference sphere from point 0 (acquired by the calibration with the master stylus), step of $0.5 \mathrm{~mm}$, until the value of $3.5 \mathrm{~mm}$ is reached. For performing the static analysis of the results, the same procedure has been repeated six times.

Reference sphere has four different orientations, while the position on the measuring table of the machine remains unchanged - factor B (Figure 2b).

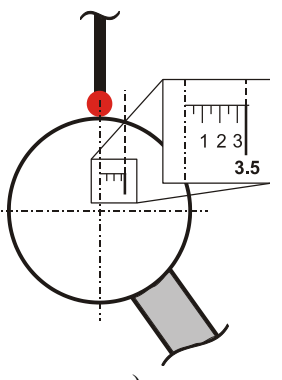

a)

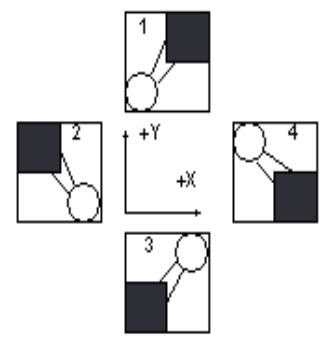

b)
Fig. 3: Influence factors. (a. calibration starting point; b. orientation of the reference sphere)

Results of this research are obtained at the temperature of $20^{\circ} \mathrm{C}$, with the same calibration method, operator and equipment, and cannot be used as reference for calibrations in variable conditions.

\section{CALIBRATION RESULTS}

It has been found that, in the total of 192 calibration procedures, the standard deviation does not exceed one tenth of a micrometer - Table 1 (Hadzistevic et al., 2011).

In this paper, the method of Analysis Of Variance is applied. Results are presented in Table 2 (Montgomery \& Runger, 2002).

\begin{tabular}{|l|l|l|l|l|l|}
\cline { 2 - 6 } \multicolumn{1}{c|}{} & DF & SS & MS & F & p \\
\hline Factor A & 7 & 0.0001 & 0.0000 & 2.90 & 0.007 \\
\hline Factor B & 3 & 0.0018 & 0.0006 & 113.14 & 0.000 \\
\hline Interaction AB & 21 & 0.0003 & 0.0000 & 2.54 & 0.001 \\
\hline Residue (error) & 160 & 0.0008 & 0.0000 & & \\
\hline Sum (total) & 191 & 0.0030 & & & \\
\hline
\end{tabular}

Tab. 1. Results of the ANOVA procedure

\section{CONCLUSIONS}

The following conclusions could be drawn out on the basis of the calibration results processing:

- Variation of the calibration results caused by selecting various calibration starting points is statistically significant at the $99 \%$ confidence level $(\mathrm{p}=0.007)$;
- Variation of the calibration results caused by changing the orientation of the reference sphere is statistically significant at the $99 \%$ confidence level $(\mathrm{p}<0.001)$; and

\begin{tabular}{|c|c|c|c|c|c|c|c|c|}
\hline B & 1 & 2 & 3 & 4 & 5 & 6 & 7 & 8 \\
\hline \multirow{6}{*}{1} & 0 & 0 & 0 & 0 & 0 & 0.1 & 0.1 & 0.2 \\
\hline & 0.1 & 0.1 & 0.1 & 0.1 & 0 & 0.1 & 0.1 & 0.3 \\
\hline & 0.1 & 0 & 0 & 0.1 & 0 & 0.1 & 0.1 & 0.2 \\
\hline & 0 & 0 & 0.1 & 0 & 0.1 & 0.1 & 0.1 & 0.3 \\
\hline & 0 & 0.1 & 0 & 0.1 & 0 & 0.1 & 0 & 0.5 \\
\hline & 0.1 & 0.1 & 0.1 & 0.1 & 0.1 & 0.1 & 0.1 & 0.1 \\
\hline \multirow{6}{*}{2} & 0.1 & 0.1 & 0.1 & 0.1 & 0.2 & 0.2 & 0.1 & 0.3 \\
\hline & 0 & 0.1 & 0.5 & 0.1 & 0.2 & 0.1 & 0.4 & 0.2 \\
\hline & 0 & 0.1 & 0.2 & 0.3 & 0.1 & 0.1 & 0.2 & 0.1 \\
\hline & 0 & 0.1 & 0.1 & 0.2 & 0.4 & 0.2 & 0.1 & 0.1 \\
\hline & 0.1 & 0.1 & 0.1 & 0.1 & 0.3 & 0.2 & 0.1 & 0.2 \\
\hline & 0.1 & 0.1 & 0.1 & 0.1 & 0.1 & 0.3 & 0.1 & 0.2 \\
\hline \multirow{6}{*}{3} & 0 & 0.2 & 0.2 & 0.2 & 0.2 & 0.2 & 0.2 & 0.3 \\
\hline & 0.2 & 0.2 & 0.2 & 0.2 & 0.2 & 0.1 & 0.2 & 0.2 \\
\hline & 0.2 & 0.2 & 0.1 & 0.2 & 0.2 & 0.1 & 0.2 & 0.2 \\
\hline & 0.2 & 0.1 & 0.2 & 0.1 & 0.1 & 0.2 & 0.1 & 0.1 \\
\hline & 0.1 & 0.1 & 0.1 & 0.2 & 0.2 & 0.1 & 0.1 & 0.1 \\
\hline & 0.2 & 0.1 & 0.1 & 0.1 & 0.1 & 0.1 & 0.1 & 0.1 \\
\hline \multirow{6}{*}{4} & 0.2 & 0.4 & 0.3 & 0.4 & 0.3 & 0.3 & 0.4 & 0.4 \\
\hline & 0.4 & 0.4 & 0.4 & 0.3 & 0.4 & 0.4 & 0.4 & 0.3 \\
\hline & 0.4 & 0.3 & 0.3 & 0.3 & 0.3 & 0.3 & 0.3 & 0.3 \\
\hline & 0.4 & 0.3 & 0.4 & 0.3 & 0.3 & 0.3 & 0.4 & 0.4 \\
\hline & 0.4 & 0.3 & 0.3 & 0.3 & 0.3 & 0.3 & 0.4 & 0.3 \\
\hline & 0.4 & 0.4 & 0.4 & 0.3 & 0.4 & 0.4 & 0.3 & 0.3 \\
\hline
\end{tabular}

Tab. 2. Standard deviation $[\mu \mathrm{m}]$

- Variation of the calibration results caused by the combined impact of the observed factors is also statistically significant at the $99 \%$ confidence level $(p=0.001)$.

Deviation of stylus and reference sphere contact point impacts calibration results at constant environmental conditions, but, as shown in table 1 , deviations if results does not exceed $0.5 \mu \mathrm{m}$. Determining impacts of variations of some other factors as stylus position and operator should be made in further research.

\section{REFERENCES}

Hadzistevic, M.; Hodolic, J.; Budak, I.; Vukelic, Dj. \& Strbac, B. (2011). Results of the Analysis on Stylus Calibration of CMM, 34 International Conference on Production Engineering, September 28-30, Serbia, ISSN:987-86-6055019-6, Trajanovic, M., pp. 143-147, University of Nis, Nis.

Montgomery, D. \& Runger, G. (2002). Applied Statistics and Probability for Engineers, John Wiley \& Sons, Inc. third edition, ISBN 0-471-20454-4, United Stated of America.

Roithmeier, R. (2007). Measurement Strategies in Contact Coordinate Metrology, Opferkuch, ISBN 978-3-98114222-8, Aalen.

Salah H. R., A. (2010). Probing System Characteristics in Coordinate Metrology. Measurement Science Review, Vol. 10, No. 4, pp. 120-129.

Weckenmann, A., Estler, T., Peggs, G. \& McMurtry, D. (2004). Probing System in Dimensional Metrology. CIRP AnnalsManufacturing Technology, 53 (2), 657-684. 